\title{
A Study of clinical and biochemical profile of Metabolic Syndrome in Acute myocardial Infarction
}

\author{
*Dr.Abhishek Raman ${ }^{1}$, Dr. Vidyapati ${ }^{2}$, Dr.M.L. Prasad ${ }^{3}$,Dr.Manoj Kumar ${ }^{4}$ \\ ${ }^{1}$ Junior Resident Academic, Department of medicine RIMS Ranchi \\ ${ }^{2}$ Associate Professor, Department of Medicine, RIMS Ranchi \\ ${ }^{3}$ Assistant Professor, Department of Medicine, RIMS Ranchi \\ ${ }^{4}$ Assistant Professor, Department of Medicine, RIMS Ranchi \\ Corresponding author: * Dr.Abhishek Raman
}

\begin{abstract}
The term "Metabolic Syndrome" has become widely used since its inception in 2001 by the NCEPATPIII, the concept of "clustering" metabolic disorders and Cardiovascular Disease (CVD) risk factors has been discussed in the scientific literature for many decades. The highest recorded prevalence worldwide is in Native Americans, with nearly 60\% of women ages 45-49 and 45\% of men ages 45-49 meeting NCEP:ATPIII criteria. Prevalence of the metabolic syndrome ranges from about 11 to 41 per cent in different regions of India. The present study is a one year cross sectional study that aims to study the prevalence of metabolic syndrome in patients with acute myocardial infarction and to assess and analyse the prevalence of individual components of metabolic syndrome in patients with acute myocardial infarction \& also its impact on the prognosis of patients with acute myocardial infarction during one week of in-hospital stay, admitted to Rajendra Institute of Medical Sciences , Ranchi. Data was collected during their hospital stay \& descriptive statistical analysis ,.Test of proportion, Chi-square $\left(\chi^{2}\right)$ Odds Ratio (OR) with $95 \%$ confidence limit were used for statistical analysis. The prevalence of metabolic syndrome in acute MI in our study (49.2\%). The body mass index (BMI) of $>25 \mathrm{~kg} / \mathrm{m}^{2}$ was found to be present in $84.6 \%$ of patients with metabolic syndrome. Serum Triglycerides was found to be higher in our study compared to other studies. The mean values of HDL-C and Waist Circumference (WC) were found to be lower in our study compared to other studies. Among the components of metabolic syndrome, low $H D L-C$ was the most prevalent component among Metabolic syndrome patients .Development of complications (heart failure, arrythmias, re-infarction and case mortality) was significantly higher in patients of metabolic syndrome compared to those without metabolic syndrome. Case mortality among patients of acute MI with metabolic syndrome was found to be $27.7 \%$.
\end{abstract}

\section{Introduction}

Cardiovascular disease (CVD) is now the most common cause of death worldwide. Today, CVD accounts for approximately $30 \%$ of deaths worldwide, including nearly $40 \%$ in high income countries and about $28 \%$ in low and middle- income countries. The global rise in CVD is the result of an unprecedented transformation in the causes of morbidity and mortality during the twenty-first centuries. This shift is driven by industrialization, urbanization, and associated lifestyle changes and is taking place in every part of the world. The metabolic syndrome (syndrome $\mathrm{X}$, insulin resistance syndrome) consists of a constellation of metabolic abnormalities (central obesity, low HDL-C(high-density lipoprotein cholesterol), hyper triglyceridemia, hyperglycemia and hypertension) that confer an increased risk of Cardiovascular Disease(CVD) and Diabetes Mellitus(DM $)^{1}$. These risk factors, when present together, increase the risk of cardiovascular disease substantially, because their combined effects are multiplicative rather than additive . Rates of Type 2 diabetes mellitus, hypertension, and lipid abnormalities are on the rise, trends that are particularly evident in children. If these risk factor trends continue, age-adjusted CVD mortality rates could increase in the coming years. ${ }^{2}$ It is estimated that around 20-25 percent of the world's adult population have the metabolic syndrome and they are twice as likely to die from and three times as likely to have a heart attack or stroke compared with people without the syndrome. In addition, people with metabolic syndrome have a five-fold greater risk of developing type 2 diabetes. The clustering of cardiovascular disease (CVD) risk factors that typifies the metabolic syndrome is now considered to be the driving force for a new CVD epidemic.The pathophysiology seems to be largely attributable to insulin resistance with excessive flux of fatty acids implicated. A pro-inflammatory state probably contributes to the syndrome. The metabolic syndrome has a correlation with the variations in genetic susceptibility, nutritional regimen, physical exercise, chronological age and gender which play direct role in the incidence of metabolic syndrome and its side effects. Early intervention of the individual components of the metabolic syndrome with intensive lifestyle changes in the form of diet changes, exercise and pharmacotherapy can prevent the development of cardiovascular disease like myocardial infarction. Community based 
programmes to promote healthy living are needed to tackle this crisis. This study has been undertaken to assess and analyse the prevalence of metabolic syndrome and its various components in patients with acute Myocardial Infarction and the impact of metabolic syndrome on the prognosis of patients with acute myocardial infarction during hospital stay.

\section{Objectives}

To study the prevalence of metabolic syndrome in patients with acute myocardial infarction admitted to Rajendra Institute of Medical Sciences , Ranchi. To assess and analyse the prevalence of individual components of metabolic syndrome in patients with acute myocardial infarction admitted to Rajendra Institute of Medical Sciences, Ranchi. To assesss the impact of metabolic syndrome on the prognosis of patients with acute myocardial infarction during one week of in-hospital stay.

\section{Materials and Methods}

In the present study 132 Patients of acute myocardial infarction admitted in RIMS, Ranchi with Acute myocardial infarction during the time period of 1 year. Patients included were those diagnosed with acute myocardial infarction (MI) based on WHO Criteria Patients more than 18 years of age . Typical rise and fall of biochemical markers of acute MI preferably Troponin plus one of the following (symptoms of ischaemia, ecg changes, development of pathological q waves, imaging evidence of new loss of viable myocardium or new regional wall motion abnormality ). Investigations done were Cardiac enzyme ,Fasting Blood Sugar (FBS), Post prandial blood sugar(PPBS) ,Complete Blood Count, Blood urea, Serum creatinine ,Liver Function Tests, PT,INR. Lipid profile - Serum Triglycerides, HDL- Cholesterol, Total Cholesterol, LDL-Cholesterol. VLDLCholesterol. 12 lead electrocardiogram(ECG) 2D - Echocardiography. Descriptive statistical analysis was performed to calculate the means with corresponding standard deviations (s.d.). analysis was made using Normal Deviate (Z), Chi-square $\left(\chi^{2}\right)$ test, Odds Ratio (OR) with 95\% confidence interval (CI), Kaplan Meier Survival analysis, Pearson Correlation Co-efficient and Multiple Logistic Regression analysis.

\section{Results}

Table-1: Prevalence Of Metabolic Syndrome In Acute MI

\begin{tabular}{|c|c|c|}
\hline PATIENTS & Number & \% \\
\hline Patients having metabolic syndrome & 65 & $49.2 \%$ \\
\hline Patients not having metabolic syndrome & 67 & $50.8 \%$ \\
\hline Total No. of patients of Acute Myocardial Infarction & 132 & $100.0 \%$ \\
\hline
\end{tabular}

Out of 132 patients of acute myocardial infarction, $\mathbf{6 5}$ patients were found to have metabolic syndrome as per modified NCEP-ATP III criteria. Prevalence of metabolic syndrome in acute MI in our study was found to be $\mathbf{4 9 . 2 \%}$.

The most common symptom in patients of myocardial infarction with metabolic syndrome and without metabolic syndrome was chest pain followed by sweating, shortness of breath, palpitation and vomiting. proportion of patients with syncope was significantly higher in patients of metabolic syndrome than that in patients without metabolic syndrome. The risk of metabolic syndrome was 8.32 times more among the patients with past history of Diabetes Mellitus as compared to the patients without past history of Diabetes Mellitus [OR-8.32] and the risk was significant .past history of hypertension (HTN)- (77.8\%) was significantly higher than those without metabolic syndrome $(29.5 \%)$. The risk of metabolic syndrome was 2.79 times more among the patients with family history of IHD as compared to the patients without family history of IHD [OR-2.79]. there was no significant association between chronic smoking and alcohol consumption and metabolic syndrome FBS >100 mg/dl and metabolic syndrome:

\begin{tabular}{|c|c|c|c|}
\hline $\begin{array}{c}\text { FBS } \\
(\mathrm{mg} / \mathrm{dl})\end{array}$ & $\begin{array}{c}\text { MI with Metabolic } \\
\text { Syndrome } \\
(\mathbf{n}=65)\end{array}$ & $\begin{array}{c}\text { MI without Metabolic } \\
\text { Syndrome } \\
(\mathbf{n}=67)\end{array}$ & TOTAL \\
\hline$\geq 100$ & 56 & 21 & 77 \\
\hline$<100$ & 9 & 46 & 55 \\
\hline TOTAL & 65 & 67 & 132 \\
\hline
\end{tabular}

The risk of metabolic syndrome was 13.62 times more among the patients with FBS $\geq 100 \mathrm{mg} / \mathrm{dl}$ as compared to the patients with FBS $<100 \mathrm{mg} / \mathrm{dl}$ [OR-13.62(5.69, 32.62); $\mathrm{p}=0.00000001]$ and the risk was significant.

SBP and metabolic syndrome:

\begin{tabular}{|l|l|l|l|}
\hline SBP & MI with Metabolic Syndrome & MI without Metabolic Syndrome & TOTAL \\
\hline
\end{tabular}

DOI: 10.9790/0853-16070298102 99 | Page




\begin{tabular}{|c|c|c|c|}
\hline$(\mathbf{m m ~ H g})$ & $(\mathrm{n}=67)$ & $(\mathrm{n}=65)$ & \\
\hline$\geq 130$ & 49 & 17 & 66 \\
\hline$<130$ & 16 & 50 & 66 \\
\hline TOTAL & 65 & 67 & 132 \\
\hline
\end{tabular}

The risk of metabolic syndrome was 9.01 times more among the patients with $\mathrm{SBP} \geq 130 \mathrm{~mm} \mathrm{Hg}$ as compared to the patients with $\mathrm{SBP}<130 \mathrm{~mm} \mathrm{Hg}$ [OR-9.01(4.09, 19.81); $\mathrm{p}=0.000001]$ and the risk was significant.

DBP and metabolic syndrome:

\begin{tabular}{|c|c|c|c|}
\hline $\begin{array}{c}\text { DBP } \\
(\mathbf{m m ~ H g})\end{array}$ & $\begin{array}{c}\text { MI with Metabolic } \\
\text { Syndrome } \\
(\mathrm{n}=65)\end{array}$ & $\begin{array}{c}\text { MI without Metabolic Syndrome } \\
(\mathrm{n}=67)\end{array}$ & TOTAL \\
\hline$\geq 85$ & 48 & 15 & 63 \\
\hline$<85$ & 17 & 52 & 69 \\
\hline TOTAL & 65 & 67 & 132 \\
\hline
\end{tabular}

The risk of metabolic syndrome was 9.78 times more among the patients with $\mathrm{DBP} \geq 85 \mathrm{~mm} \mathrm{Hg}$ as compared to the patients with $\mathrm{DBP}<85 \mathrm{~mm} \mathrm{Hg}[\mathrm{OR}-9.78(4.41,21.72) ; \mathrm{p}=0.000001]$ and the risk was significant.

Serum Triglycerides (TGs)and metabolic syndrome

\begin{tabular}{|c|c|c|c|}
\hline $\begin{array}{c}\text { TGs } \\
(\mathbf{m g} / \mathbf{d l})\end{array}$ & $\begin{array}{c}\text { MI with Metabolic } \\
\text { syndrome } \\
(\mathbf{n}=65)\end{array}$ & $\begin{array}{c}\text { MI without Metabolic Syndrome } \\
(\mathbf{n}=67)\end{array}$ & TOTAL \\
\hline$\geq 150$ & 53 & 15 & 68 \\
\hline$<150$ & 12 & 52 & 64 \\
\hline TOTAL & 65 & 67 & 132 \\
\hline
\end{tabular}

The risk of metabolic syndrome was 15.31 times more among the patients with TGs $\geq 150 \mathrm{mg} / \mathrm{dL}$ as compared to the patients with TGs $<150 \mathrm{mg} / \mathrm{dl}$ [OR-15.31(6.54, 35.82); $\mathrm{p}=0.000001$ ] and the risk was significant.

Low HDL-C and metabolic syndrome in males

\begin{tabular}{|c|c|c|c|}
\hline $\begin{array}{c}\text { HDL } \\
(\mathbf{m g} / \mathbf{d l})\end{array}$ & $\begin{array}{c}\text { MI with Metabolic syndrome } \\
(\mathrm{n}=46)\end{array}$ & $\begin{array}{c}\text { MI without Metabolic Syndrome } \\
(\mathbf{n}=50)\end{array}$ & TOTAL \\
\hline$<40$ & 42 & 18 & 60 \\
\hline$\geq 40$ & 4 & 32 & 36 \\
\hline TOTAL & 46 & 50 & 96 \\
\hline
\end{tabular}

The risk of metabolic syndrome was 18.66 times more among the males with HDL<40 mg/dl as compared to the males with HDL $\geq 40 \mathrm{mg} / \mathrm{dl}$ [OR-18.66(5.75, 60.56); $\mathrm{p}=0.00001]$ and the risk was significant.

Low HDL-C and metabolic syndrome in females:

\begin{tabular}{|c|c|c|c|}
\hline $\begin{array}{c}\text { HDL } \\
(\mathbf{m g} / \mathbf{d l})\end{array}$ & $\begin{array}{c}\text { MI with Metabolic } \\
\text { syndrome }(\mathrm{n}=19)\end{array}$ & MI without Metabolic Syndrome (n=17) & TOTAL \\
\hline$<50$ & 17 & 6 & 23 \\
\hline$\geq 50$ & 2 & 11 & 13 \\
\hline TOTAL & 19 & 17 & 36 \\
\hline
\end{tabular}

The risk of metabolic syndrome was 15.58 times more among the females with HDL $<50 \mathrm{mg} / \mathrm{dl}$ as compared to the females with HDL $\geq 50 \mathrm{mg} / \mathrm{dl}[\mathrm{OR}-15.58(2.65,91.57) ; \mathrm{p}=0.0007]$ and the risk was significant.

Waist Circumference (WC) and metabolic syndrome in males:

\begin{tabular}{|c|c|c|c|}
\hline $\begin{array}{c}\text { WC } \\
(\mathbf{c m})\end{array}$ & $\begin{array}{c}\text { MI with Metabolic } \\
\text { syndrome } \\
(\mathbf{n = 4 6})\end{array}$ & $\begin{array}{c}\text { MI without Metabolic } \\
\text { Syndrome } \\
(\mathbf{n = 5 0})\end{array}$ & TOTAL \\
\hline$>90$ & 30 & 8 & 38 \\
\hline$<90$ & 16 & 42 & 58 \\
\hline TOTAL & 46 & 50 & 96 \\
\hline
\end{tabular}


The risk of metabolic syndrome was 9.84 times more among the males with $\mathrm{WC}>90 \mathrm{~cm}$ as compared to the males with $\mathrm{WC}<90 \mathrm{~cm}[\mathrm{OR}-9.84(3.73,25.95) ; \mathrm{p}=0.000002]$ and the risk was significant.

WC and metabolic syndrome in females

\begin{tabular}{|c|c|c|c|}
\hline $\begin{array}{c}\text { WC } \\
(\mathbf{c m})\end{array}$ & $\begin{array}{c}\text { MI with Metabolic } \\
\text { Syndrome } \\
(\mathrm{n}=19)\end{array}$ & $\begin{array}{c}\text { MI without Metabolic } \\
\text { Syndrome } \\
(\mathrm{n}=17)\end{array}$ & TOTAL \\
\hline$>80$ & 17 & 7 & 24 \\
\hline$<80$ & 2 & 10 & 12 \\
\hline TOTAL & 19 & 17 & 36 \\
\hline
\end{tabular}

The risk of metabolic syndrome was 12.14 times more among the females with $\mathrm{WC}>80 \mathrm{~cm}$ as compared to the females with $\mathrm{WC}<80 \mathrm{~cm}[\mathrm{OR}-12.14(2.09,70.22) ; \mathrm{p}=0.007]$ and the risk was significant.

Case mortality and metabolic syndrome :

\begin{tabular}{|c|c|c|c|}
\hline Outcome & $\begin{array}{c}\text { MI with Metabolic } \\
\text { Syndrome } \\
(\mathbf{n = 6 5})\end{array}$ & $\begin{array}{c}\text { MI without Metabolic } \\
\text { Syndrome } \\
(\mathbf{n}=\mathbf{6 7})\end{array}$ & TOTAL \\
\hline Improved & $\mathbf{4 7}$ & $\mathbf{6 3}$ & $\mathbf{1 1 0}$ \\
\hline Died & $\mathbf{1 8}$ & $\mathbf{4}$ & $\mathbf{2 2}$ \\
\hline TOTAL & 65 & 67 & 132 \\
\hline
\end{tabular}

Test of proportion showed that among the patients with metabolic syndrome case mortality was significantly higher $(27.7 \%)(\mathrm{p}<0.01)$.

Prevalence Of Individual Components Of Metabolic Syndrome In Patients Of Acute Mi With Metabolic Syndrome:

\begin{tabular}{|c|c|}
\hline Components Of Metabolic Syndrome & Prevalence In Metabolic Syndrome (N=65) \\
\hline Low Hdl-C Levels & $90.8 \%$ \\
\hline Fbs $>100 \mathrm{Mg} / \mathrm{Dl}$ & $86.2 \%$ \\
\hline Increased Triglyceride Levels $(>150 \mathrm{Mg} / \mathrm{Dl})$ & $81.5 \%$ \\
\hline Sbp $>130 \mathrm{Mm} \mathrm{Hg}$ & $75.4 \%$ \\
\hline Dbp $>85 \mathrm{Mm} \mathrm{Hg}$ & $73.8 \%$ \\
\hline Elevated Wc & $72.3 \%$ \\
\hline
\end{tabular}

\section{Discussion}

This was a hospital-based, cross-sectional observational study. 132 cases of Acute Myocardial Infarction (AMI) admitted to the ICCU\& Cardiology wards of RIMS , Ranchi. during the period between $1^{\text {st }}$ Sept, 2015 to Oct $31^{\text {st }}, 2016$ were studied. All cases were included keeping in mind the inclusion and exclusion criteria. Prevalence of metabolic syndrome (as defined by revised NCEP ATP III criteria ) in Acute MI was $49.2 \%$ in our study, which is comparable to the prevalence rates of $46 \%, 49 \%, 49.8 \%$ and $47.14 \%$ found in studies conducted by Zeller et al., Prasad SB, Babic Z et al and Sarkar S respectively suggesting that metabolic syndrome, is very common among patients with coronary artery disease /myocardial infarction, because almost 1 in 2 patients had metabolic syndrome and that it is associated with advanced vascular damage. Our study confirms the high prevalence of metabolic syndrome in patients with MI,suggesting that the metabolic syndrome has clinical utility in identifying patients at increased risk of AMI .The mean age of acute MI with metabolic syndrome in our study was almost the same(59.73 yrs) compared to the mean age found in studies conducted by Levantesi G (59.0 yrs) and Pandey S et al. (60.69 yrs). In the present study, past history of diabetes mellitus, hypertension and family history of IHD was more in patients with Metabolic syndrome compared to patients without Metabolic syndrome, which was statistically significant. However, there was no statistically significant difference in the association between smoking, alcohol consumption and metabolic syndrome.Our study showed a higher prevalence of known cases of diabetes mellitus and family history of IHD among patients having metabolic syndrome, compared to other studies. In our study, the most prevalent component of metabolic syndrome was low HDL-C $(90.8 \%)$ followed by increased fasting blood sugar $(86.2 \%)$, increased serum triglycerides $(81.5 \%)$, hypertension $(75.4 \%)$, and elevated waist circumference $(72.3 \%)$. This result is similar to the one obtained by Pandey $\mathrm{S}$ et al. and Al-Aqeedi et al. who also found low HDL-C to be the most prevalent component along with increased FBS (77.2\%). The mean value of Fasting Blood Sugar(FBS), Blood Pressure (SBP \& DBP), Serum Triglycerides was found to be higher in our study compared to other studies. 


\section{Conclusion}

There is high prevalence of metabolic syndrome and its individual components in patients of acute myocardial infarction, suggesting that the metabolic syndrome has clinical utility in identifying patients at increased risk of Acute MI. The presence of metabolic syndrome in patients of acute myocardial infarction worsens the prognosis of such patients. Complications like heart failure, ventricular tachycardia/ventricular fibrillation, re-infarction and mortality were significantly higher in patients having metabolic syndrome.Low HDL-C was the most prevalent component among patients having metabolic syndrome, followed by increased fasting blood sugar levels. To conclude, our findings clinch the importance of the metabolic syndrome as a significant risk factor for cardiovascular disease, particularly myocardial infarction. This reaffirms the need to develop stringent strategies for controlling this syndrome and also its individual components. Hence, prevention, detection and optimal management of metabolic syndrome is likely to reduce cardiovascular risk and early management will save the precious human lives.

\section{References}

[1]. Eckel RH.The Metabolic Syndrome. In : Fauci AS, Kasper DL, Hauser SL, Longo DL, Jameson JL, Loscalzo J editors. Harrison's Principles of Internal Medicine.18 ${ }^{\text {th }}$ edition.New York:McGraw-Hill;2012. p. 1992-1998.

[2]. Gaziano TA, GazianoJM. Epidemiology of Cardiovascular disease. In:Fauci AS, Kasper DL, Hauser SL, Longo DL, Jameson JL, Loscalzo J editors. Harrison's Principles of Internal Medicine. 18th edition. New York: McGraw-Hill; 2012. p.1811-1816.

[3]. The IDF consensus worldwide definition of the metabolic syndrome.Available at http://www.idf.org/webdata/docs/IDF_Metasyndrome_definition.pdf.2005(accessed on May 10, 2012)

[4]. Marjani A.A Review on Metabolic Syndrome.J EndocrinolMetab. 2012; 2(4):166-170.

[5]. Eckel RH, Grundy SM, Zimmet PZ. The metabolic syndrome.Lancet.2005; 365:1415-28.

[6]. Avogaro P, Crepaldi G. Essential hyperlipidemia, obesity and diabetes. Diabetologia.1965; 1: 137-142.

"Dr.Abhishek Raman. "A Study of clinical and biochemical profile of Metabolic Syndrome in Acute myocardial Infarction ." IOSR Journal of Dental and Medical Sciences (IOSR-JDMS) 16.7 (2017): 98-102. 